\title{
BRILHANTE ILUSÃO
}

\section{SHINY ILLUSION}

Jussara de Freitas Queles Assis*

\begin{abstract}
RESUMO
No momento em que comemoramos os 300 anos de Minas, trazemos à reflexão os caminhos e descaminhos percorridos para a consolidação do Estado e sua relevantecontribuição para o desenvolvimento do Brasil. O presente artigo faz um recorte sucinto do período colonial aos dias atuais da vida mineira em especial da contribuição econômico-financeira do Estado para o Brasil. Obviamente não é possível descrever a evolução mineira sem considerar a história de colonização e independência do Brasil. Minas Gerais sempre contribuiu de maneira expressiva na formação do país, e isto em diversos aspectos, como, econômico, cultural, financeiro. Minas foi também palco de intensa luta pela liberdade o que refletiu em mudanças significativas tanto no Estado, como em todo território brasileiro.
\end{abstract}

Palavras-Chave: Ilusão. Riqueza. Escassez. Luta.

\begin{abstract}
As we celebrate 300 years of Minas, we bring to reflection the paths and detours taken towards the consolidation of the State and its relevant contribution to the development of Brazil. This article makes a succinct cut from the colonial period to the present days of Minas Gerais life, especially the economic-financial contribution of the State to Brazil. Obviously, it is not possible to describe the evolution of Minas Gerais without considering the history of colonization and independence in Brazil. Minas Gerais has always contributed significantly to the formation of the country, and this in various aspects, such as economic, cultural, financial. Minas was also the scene of an intense struggle for freedom, which reflected in significant changes both in the State and in the entire Brazilian territory.
\end{abstract}

Keywords: Illusion. Wealth. Scarcity. Fight.

A busca pelas riquezas auríferas trouxe para o território mineiro povos advindos de diversos locais do Brasil que adentravam as matas fechadas em busca de pedras preciosas e riquezas. Essa busca frenética por metais ocasionava embates e disputas sangrentas entre os extrativistas trazendo para a história conflitos entre os estados brasileiros como a Guerra dos Emboabas, as Inconfidências e a Conjuração de 1789. Outro embate também ocorria entre os interesses econômicos da metrópole na extração do ouro e os nativos indígenas quepouco se importavam com ouro, mas detinha elevado apreço a terra e "dificultava" o povoamento dos sertões mineiros.

No século XVI o Estado de Minas brilhava com os achados valiosos de ouro ea extração

Artigo submetido em 21 de julho de 2021 e aprovado em 10 de setembro de 2021.

* Graduanda em Direito pela Pontifícia Universidade Católica de Minas Gerais. E-mail: jfqassis@sga.pucminas.br. 
mineradora aurífera era sua principal mola propulsora da economia do Brasil, atraindo para seu interior várias pessoas de outros estados em busca de riquezas. Nesse período as minas eram a direção de diversos povos de outras capitanias que na intenção de encontrar cada vez mais ouro se embrenhavam pelas matas fixavam e demarcavam territórios no sertão buscando sempre a extração de ouro e metais preciosos. O movimento bandeira consistia no estabelecimento de povos vindos de outros estados como São Paulo que se estabeleciam nos sertões ao encontrarem as minas, demarcava o território com bandeiras, daí surgiu o nome do movimento. A esse movimento também é atribuído o processo de captura repressão aos povos indígenas ocorrido no século seguinte conforme descrito por Romeiro e Botelho (2013). Com tanta afluência de estrangeiros, fato é que ocorriam cada vez mais embates para demarcação de território e dominação das minas o que levou a realeza também interessada nas riquezas das minas, programar maiorcontrole e fiscalização da extração e exportação do ouro, instituindo também homens para demarcarem o sertão. A ação das bandeiras contribuiu para desbravar Minas e revelar riquezas imensuráveis.

Esse período de Brasil-colônia as divisões territoriais eram por capitanias e Minas agregava-se a capitania de Rio de Janeiro e São Paulo. Era um vasto território que dificultava o controle da Corte Portuguesa e os conflitos entre os colonos eram constantes.

No século XVIII a coroa interessada em manter maior controle das extrações auríferas resolve separar as capitanias de São Paulo e Mina do Ouro da capital Rio de Janeiro. É nesse momento que a guerra pela apropriação das riquezas das minasse aferra e paulistas deflagram a Guerra dos Emboabas, que consistia na luta de paulistas em defender o território mineiro contra qualquer invasor, em especial os portugueses.

Para efetivar o controle e mitigar as pelejas pela posse dos territórios e das minas, a Coroa Portuguesa decide por separar as capitanias São Paulo e Mina do Ouro, fazendo surgir, em 1720, a capitania de Minas Gerais. O Estado de Minas Gerais teve sua criação com o objetivo de controle da arrecadação da extração do ouro uma das principais fontes de renda da então capitania que consequentemente contribuía para o enriquecimento de Portugal. A decisão de separar as capitanias Minas e São Paulo foi também uma tentativa de controlar as disputas e guerras recorrentes entre os extrativistas por causa das minas de ouro e aumentar a arrecadação da Coroa.

Importante salientar que Minas Gerais sempre exerceu importante papel no desenvolvimento econômico do país, seja fornecendo ouro, seja propiciando a geração de insumos agrícolas, minerais e o desenvolvimento comercial do país.

O desejo desenfreado da Coroa na obtenção de ouro permitiu que o desenvolvimento do Estado em outras áreas da economia ficasse estagnado por um bom tempo, a ponto de em um dado momento da história, Minas ser considerado como um estado fadado ao fracasso, pois a falta de abastecimento, principalmente de alimento, afetava imensamente o trabalho de mineração, e a fome impedia o trabalho nas minas obrigando os trabalhadores a se refugiarem nas matas em busca de alimento fornecido pela flora e fauna. Essa interiorização dos trabalhadores e diminuição da mão de obra para a extração aurífera fez com que a Coroa providenciasse abertura pela Capital Rio de Janeiro para o abastecimento de alimento da capitania de Minas, bem como o favorecimento do plantio ao longo dos leitos dos rios.

Resende, Villalta (2013) destaca que os anos setecentos foram, portanto, marcados por guerra defensiva e ofensiva que contavam com a presença dos índios nativos para proteção de seu habitat e vida simples e mística de total respeito a natureza dela extraindo somente o necessário para o seu sustento, e de outro lado oEstado querendo povoar o território mineiro e aumentar os lucros auferidos pela mineração. Nessa guerra os governadores apoiados pela Coroa declaram guerra aos índios botocudos e esses em contrapartida resistem na defesa de seu espaço, gerando um momento de tensão com mortes que dizimam a população nativa. 
Como toda história desde o descobrimento do Brasil, esse momento é triste, sombrioe revela supervalorização à riqueza em detrimento da vida. Gonzaga retrata em sua obra Marilia de Dirceu, Lira III, parte III, que é oculto aos olhos a opressão de muitos para o enriquecimento de poucos; e a constante degradação do meio ambiente para dele extrair riquezas.

\footnotetext{
Tu não verás, Marília, cem cativos

Tirarem o cascalho e a rica terra,

Ou dos cercos dos rios caudalosos,

Ou da minada serra.

Não verás separar ao hábil negro

Do pesado esmeril a grossa areia,

E já brilharem os granetes de ouro

No fundo da bateia.
}

Apesar de nesse período a extração do ouro não estar mais tão promissoraainda assim os sertões mineiros continuavam ser atração para aqueles que acreditavam ser possível encontrar novas minas. O interesse econômico ainda eradepositado em grande escala no descoberto de novas fontes do metal precioso.

Essa busca "cega" desencadeou problemas sérios para os mineiros, que desabastecidos viam sua principal fonte de riqueza se esvair e o descortinar de uma nova forma de vida se torna não somente necessário, mas imprescindível para continuidade da capitania mineira. Resende e Villalta (2013) ressalta que os memorialistas alertavam para o perigo de manter a caçada pelas minas a qualquer custo e o desprezo por outras formas de extração de riquezas do território mineiro, como agricultura, criação de gado, entre outros; ainda assim a Coroa pressionava para que se descobrissem outras minas e essa "esperança" de riqueza fácil aprisionava ainda mais índios, desvalidos, e o que denominavam de vadios. Certo é que quando se fecha os olhos para o horizonte das possibilidades que nos cerca, a riqueza se esvai e nos escapam às mãos.

$\mathrm{Na}$ busca pelo ouro os mineiros esqueciam-se da vida, e a certeza de que haveria minas não alcançadas fazia com que embrenhassem nas matas insalubres ecolocavam em risco a saúde. "Quanto mais intensos eram os fluxos de mineradores, mais se evidenciava a escassez de produtos, principalmente os destinados à alimentação (Romeiro, Adriana, 2013, p. 13)."

A importação de alimentos de outros estados era dificultada pela falta de estradas ou canais liberados para entrada de alimento no Estado. Somente depois do acordo dos governadores do Estado de Minas e do Espirito Santo em 1800 quefoi possível abertura dos canais do Rio Doce para importação de abastecimento dapopulação mineira. Mas ainda assim os alimentos que chegavam eram comercializados em altos preços que dificultavam o abastecimento satisfatório do povo mineiro.

A solução, porém, não estava somente na abertura de navegação pelo Rio Doce que segundo a história era de difícil navegação e a essa dificuldade é acrescentado, as condições climáticas da floresta que propiciava o aumento de doenças e especial a malária, esses ocorridos dificultavam o progresso da vida mineira. Necessário era que novas fontes de prosperidade fossem encontradas paraa mantença da capitania que chegou ser considerada por alguns como à beira da extinção.

Conforme Romeiro e Botelho (2013) outros fatores também contribuíam para o desabastecimento, como a distância das minas e as regiões que produziam alimentos, as péssimas condições de acesso ao sertão, precariedade dos meios de transporte, a falta de moedas e a multiplicidade de tributos que incidiam nas mercadorias importadas pelos mineiros. Diante dessa situação preocupante de fomee escassez, Minas Gerais se reinventa na plantação de hortaliças, criação de víveres e de gado e de porco, ao ponto de ao final do século ser considerado umdos principais fornecedores de alimento para o país. 
A diminuição dos achados de ouro fez com que se pensasse que seria o fim da província mineira que sofria pela falta de estradas e meios de navegação para o abastecimento de alimentos. Outro entrave para a continuidade da província estava na imensa territorialidade e população escassa; e ainda, a necessidade dos índios habitantes da terra de proteger seu habitat, fazia com que as disputas sangrentas entre os militares instituídos pelo Estado e os nativos fossem frequentes. Porém diante das dificuldades o povo mineiro se sobressai evidenciando não só a continuidade do Estado bem como contribuindo de forma significativa para o desenvolvimento do país. O início de plantio de hortaliças, a criação de víveres, mostrou uma Minas com solo fértil e com novas possibilidades para continuidade da vida no sertão. Aos poucos o estado foi se tornando autossuficiente no abastecimento alimentar. Em cada região de Minas um produto era desenvolvido e acapitania foi se tornando um polo da gastronomia brasileira com descobertos de refeições tais como o feijão de tropeiro, o pé de moleque (melaço da cana-de-açúcare amendoim) e diversos outros pratos foram sendo criados para saciar a fome e ainda hoje a cozinha mineira é referência para o Brasil e o mundo.

A produção agrícola e produção de minério de ferro aliadas ao desenvolvimento tecnológico e à forma de produção em escala foram indispensáveispara o Brasil no momento em que a Revolução Industrial moldava e mudava os rumos de todo o mundo. Nesse cenário, Minas se destaca com o fornecimento do minério de ferro não valioso como o ouro, mas, muito útil para alavancar a economia brasileira.

Os anos setecentos foram marcados por lutas; luta pela busca do ouro, pelademarcação do território, luta por sobrevivência. Podemos afirmar que o povo mineiro é marcado em sua constituição por resiliência e criatividade em busca da sobrevivência.

Um movimento histórico que marca os fins dos anos setecentos é a Inconfidência Mineira, capitaneada pelo Alferes Joaquim José da Silva Xavier e composta por intelectuais, donos de terra, clérigos e militares que queriam com omovimento barrar a instauração da derrama proposta pela Corte portuguesa paraampliar a taxação de impostos recaindo a cobrança sobre todos os moradores daCapitania. A opressão da Coroa despertou a revolta desse grupo seleto da sociedade que baseados nos princípios iluministas dominantes dos ideais de liberdade da época criaram o movimento com objetivo de barrar a ampliação da taxação e ainda se libertar dos desmandos da Coroa Portuguesa. A Inconfidência buscava a liberdade econômica de Minas e também do Brasil ao propor alteração da forma de governo, e tentar barrar a excessiva taxação da realeza sobre a colônia, em especiala capitania de Minas que por sua região rica em ouro era devastada pela ganância real. O movimento não logrou êxito conforme o desejado, mas, nos deixou legados valiosos de ambição, conquista e persistência nos objetivos de crescer e contribuir positivamente para o desenvolvimento do Brasil.

No final do século XVIII a extração de ouro já não se mostrava tão atraente; apesar de ainda um grupo buscar com insistência os novos descobertos de minas; outros com visão mais ampla já vislumbravam outras formas de extração de riquezase de permitir a sobrevivência e a continuidade da capitania. Nesse novo caminhar a agricultura, a criação e exportação de gado, a extração de outros metais e de ferro, estes não tão valiosos como o ouro, mas, igualmente importantes para o desenvolvimento econômico do país.

Como sempre na história de Minas, os avanços são galgados não com pouca luta e enfrentamento de dificuldades diversas, nesse período a alavanca da prosperidade dependia da abertura de caminhos para importação e exportação de bens e produtos, e a solução apresentada era a abertura da navegação pelo Rio Doce e a territorialização do sertão intermédio para aumento da produção agrícola e criação de gado. O problema, porém, apresentado pelos governadores da época eram os índios nativos "botocudos" que não aceitavam de bom grado a invasão de suas terras e a baixa ocupação do solo nos sertões. A solução apresentada pelo Governador Ataíde e Mello foi a extinção dos índios "botocudos" a remoção das matas e dos 
pântanos, para combater os surtos de malária e o envio de pessoas em situação de vulnerabilidade, (endividados, vadios, condenados, etc) para ocupação do sertão e cultivo do solo para alcance das riquezas escondidas no territóriomineiro.

Mais uma vez a história de Minas carrega um contraste entre a destruição do meio ambiente e a desvalorização da vida em busca de riqueza material. Com a aprovação da Coroa, aumentou o poderio militar para a ofensiva proposta pelo entãogovernador Ataíde e Mello e o que presenciamos é um momento sangrento com resultado de várias mortes e servidão dos nativos aos anseios de enriquecimento do Estado.

Os anos oitocentos são marcados pela mudança de perspectiva da vidaeconômica de Minas Gerais. Ideias de expansão da cultura de exportação e da criação de gado começam se apresentar como formas de fomento do comércio e ampliação da riqueza mineira. Figuras importantes como Antônio Pires da Silva Pontes Leme, destacam a inutilidade da ilusão de riqueza pela mineração de ouro e ressalta a necessidade de atentar para novas formas de se adquirir o sustento e sobrevivência da vida mineira. Resende e Villalta (2013) destaca o conselho fornecido por Leme (1987), que propõe "Utilizar as famílias descidas das Minas ou vindas das Ilhas dos Açores" e dar moratória aos "homens de fábrica", que viessem se estabelecer, naqueles sertões" (p. 56). Propondo com isso o povoamento da capitania e o desenvolvimento de atividade agrícola e industrial. Esse é o pensamento dominante no início do século XIX.

Após denso embate com os índios ocorre uma mudança na forma de combater a resistência indígena e conseguir adentrar nos sertões, qual seja a adesão da mão de obra indígena para obtenção de riqueza. Esse processo denominado de civilização do índio a partir da mistura dos povos indígenas e brancos a fim de alavancar a economia, foi trágico para o povo indígena que teve sua forma de vida alterada pela intromissão de outros povos. Apesar de se proibir a escravidão dos índios, obrigá-los a uma vida forjada pelo ferro e costumes não lhes inerentes fez com que tribos inteiras fossem dizimadas.

A penetração da frente de ocupação demográfica, no entanto, foi lenta e, dessa forma, se criou um tempo dilatado com intensos contatos interétnicos, hibridismo sociocultural e diluição genética das populações indígenas na sociedade envolvente. (Resende, Villalta, 2013, p. 64).

Com o vencimento da primeira barreira "extinção dos índios", Minas ainda teria que enfrentar outros entraves para o desenvolvimento econômico. A navegaçãopelo Rio Doce era um dos objetivos perseguidos para o desenvolvimento econômico da capitania. E esse intento só foi concluído em meados do século com a ocupação da Bacia Hidrográfica.

$\mathrm{O}$ aumento da produção e exportação de café produto que se tornou principal atividade econômica da província contribuiu para o povoamento da parte meridional do Rio Doce, e a produção da pecuária de corte afluiu população para a parte setentrional da Bacia Hidrográfica do Rio Doce, contribuindo de forma significativa para o desenvolvimento da infraestrutura de transportes provocando aumento de industrialização do país. Alia-se à produção de café e pecuária a agricultura de subsistência que não influi de maneira forte para a industrialização, mas, contribui para o povoamento dos sertões intermédios.

A movimentação da economia mineira nas últimas décadas do século XIX, ajudada pelo desenvolvimento da cultura do café e pela revolução que as ferrovias provocaram no sistema de transportes, deu ao processo de industrialização regional uma fisionomia bem definida. (Resende, Villalta, 2013, p. 370)

O período foi marcado por evolução e recessão econômica, chegando ao fim do século 
com uma política de Estado intervencionista para alavancar a economiada região das Minas Gerais.

Minas Gerais ao longo de sua trajetória se mostrou um terreno repleto de diversas riquezas, minerais como ouro e diamantes, minério de ferro, madeira, solo fértil, e a cada descoberta dessas riquezas o Estado se mostra promissor e altamente importante para o desenvolvimento nacional e se destaca no âmbitointernacional.

O século XX traz uma nova alteração do produto propulsor da economia saindo da cafeicultura e se concentrando na produção siderúrgica e crescimento no aproveitamento dos recursos minerais. A criação de ferrovias amplia a escoação dasriquezas de Minas a fazendo destacar como polo de riqueza e prosperidade. Não se pode olvidar que as riquezas advindas da extração do minério de ferro contribuem para evolução siderúrgica, mas, também trazem em seu escopo um quadro de destruição e que por vezes são catastróficos por demais. As montanhas de Minas parecem refletir sua história de altos e baixos, beleza e hediondez, riqueza e pobreza. É nesse caminhar diário que Minas prossegue e vence os obstáculos que lhe são propostos; erra e acerta, mas, não para de avançar.

Problemas como os descritos no início do Brasil Colônia já não assombram mais o povo mineiro, pois sua população hoje é numerosa e cheia de talentos quese revelam e destacam em diversas áreas da vida econômica, social e cultural.

Dos movimentos de afluência de estrangeiros, Minas extraiu a beleza da diversidade e se constituiu em um estado diversificado que se destaca pela alta gastronomia, pelo talento artístico e cultural.

Apesar dos momentos de tensão e luta nesses 300 anos de Minas Gerais temos muito a comemorar. Entre lágrimas e sorrisos construímos um Estado relevante para o cenário brasileiro, aprendemos com nossos erros e valorizamos nossos acertos.

Minas é um Estado de tradição, que se desenvolve e alcança patamares relevantes no cenário nacional e internacional. As adversidades não serviram de condão para desanimar o povo mineiro.

Importante salientar que Minas sempre foi relevante para o desenvolvimento do país tanto economicamente quanto culturalmente. De repente por sua formação de povos oriundos de diversas partes do Brasil, Minas apresenta uma forma de vida eclética que se manifesta na arte, cultura e no modo de vida do mineiro.

Minas Gerais desde a sua fundação vem ampliando seus horizontes, modificando sua forma de produção, se tornando polo da moda e da gastronomia.

Minas Gerais também se destaca no mundo artístico, principalmente no mundo musical.

Estado que alia tradição com inovação. O povo mineiro possui uma forma peculiar na fala e na forma de lidar com as situações que a vida lhe oferece.

Minas não é só ouro, só ferro, só pau e pedra, Minas é talento é música e dança, festa e folclore.

O povo mineiro carrega consigo a diversidade de sua formação e nada melhorpara descrevê-lo como o trecho do poema de Carlos Drummond de Andrade

Ser Mineiro é dizer "uai", é ser diferente,é ter marca registrada, é ter história.

Ser Mineiro é ter simplicidade e pureza,humildade e modéstia, coragem e bravura, fidalguia e elegância.

$\cdots$

Ser Mineiro é ser religioso e conservador,é cultivar as letras e artes,

é ser poeta e literato,

é gostar de política e amar a liberdade,é viver nas montanhas,

é ter vida interior,é ser gente. 
Os contrastes fazem parte da história de Minas, estão impregnados no modo de ser do mineiro e são eles que nos fazem ter visão ampla do mundo, que nos impulsionam para as conquistas.

Parabéns, Minas Gerais, e que venham mais 300 anos de história e deprosperidade.

\section{REFERÊNCIAS}

ANDRADE, Carlos Drummond de. Petrópolis: Vozes, 1976. (Coleção Poetas Modernos do Brasil, 4).

GONZAGA, Tomás Antônio. Os melhores poemas. Sel. Alexandre Eulálio. SãoPaulo: Global, 1983. (Os Melhores poemas).

RESENDE, Maria Efigênia Lage de. VILLALTA, Luiz Carlos (orgs.). História de Minas Gerais: A província de Minas. Vol. 1. Belo Horizonte: Autêntica, 2013.

ROMEIRO, Adriana. BOTELHO, Ângela Vianna (orgs.). Dicionário histórico das Minas Gerais: período colonial. $3^{a}$ edição, Vol. 1. Belo Horizonte: Autêntica, 2013. 